\title{
Perancangan Model Filter Air Dengan Serbuk Keramik Sebagai Media Filter
}

\section{Design of a Water Filter Model with Ceramic Powder for Filter Media}

\author{
Bambang Wisaksono ${ }^{1}$, Hari Dwi Wahyudi ${ }^{*}$, and Syarifah Aini ${ }^{2}$ \\ ${ }^{1}$ Teknik Pertambangan, Univ. Pembangunan Nasional Veteran, Jl. SWK 104 Lingkar Utara, Yogyakarta, Indonesia 55283 \\ ${ }^{2}$ Teknik Sipil, Univ. Widya Dharma, Jl Ki Hajar Dewantara, Klaten, Indonesia 57438.
}

\section{Artikel histori :}

Diterima 27 Februari 2021 Diterima dalam revisi 06 April 2021 Diterima 28 April 2021 Online 10 Mei 2021

\begin{abstract}
ABSTRAK: Fenomena yang ada bahwa air tanah di daerah komplek kampus terpadu UPN Veteran Yogyakarta berbau dan berwarna coklat kemerahan, dan apabila air tersebut juga menimbulkan endapan pada bak penampung air. Berdasarkan fenomena tersebut, maka diduga bahwa air tanah tersebut mengandung zat besi (Fe) dan Mangan (Mn) yang cukup tinggi. Guna mengatasi hal tersebut maka diperlukan upaya mereduksi kadar zat besi (Fe) dan Mangan (Mn) sesuai dengan peraturan yang disyaratkan. Fokus utama dari penelitian ini adalah membuat suatu model purwarupa instrumen filter air bersih untuk menurunkan kadar besi (Fe) dan Mangan (Mn) dalam air sumur yang berfungsi untuk memfiltrasi air sumur menjadi air bersih yang layak konsumsi sesuai dengan standar Peraturan Menteri Kesehatan Republik Indonesia Nomor 32 Tahun 2017. Berdasarkan hasil uji kualitas air sumur yang dilakukan, 4 parameter kualitas air mempunyai nilai yang melampaui ambang batas baku mutu yang disyaratkan, yaitu nilai pH, kadar Fe, kadar Mn, dan kadar Cd. Susunan komposisi media filter air dirancang berdasarkan hasil analisa uji awal kualitas air sumur sebagai contoh air baku. Tabung filter air terbuat dari pipa PVC diameter 4 inchi, dengan panjang $80 \mathrm{~cm}$. Komposisi media filter, terdiri dari: karbon aktif, tebal $25 \mathrm{~cm}$; serbuk keramik, tebal $25 \mathrm{~cm}$; pasir vulkanik, tebal $15 \mathrm{~cm}$; dan kerikil, tebal $10 \mathrm{~cm}$.
\end{abstract}

Kata Kunci: Besi (Fe); Kadmium (Cd); Mangan (Mn); Kualitas; Air.

ABSTRACT: Groundwater in the UPN Veteran Yogyakarta integrated campus complex smells and has a reddish brown color, and if the water also causes sediment in the water reservoir, it is assumed that the groundwater contains quite high levels of Ferro (Fe) and Manganese (Mn). Efforts are needed to reduce levels of Ferro $(\mathrm{Fe})$ and Manganese $(\mathrm{Mn})$ in accordance with the required regulations. The main focus of this research is to make a prototype of a clean water filter instrument to reduce levels of Ferro (Fe) and Manganese (Mn) in well water which functions to filter well water into clean water that is fit for consumption in accordance with the standards of the Regulation of the Minister of Health of the Republic of Indonesia number 32 at 2017. Based on the results of the well water quality test, 4 water quality parameters have a value that exceeds the required quality standard threshold, namely the $\mathrm{pH}$ value, Ferro $(\mathrm{Fe})$ content, Manganese $(\mathrm{Mn})$ content, and Cadmium $(\mathrm{Cd})$ content. The composition of the water filter media composition is designed based on the results of the preliminary test analysis of the quality of well water as an example of raw water. The water filter tube is made of 4 inch diameter PVC pipe with a length of $80 \mathrm{~cm}$. The composition of the filter media consists of: activated carbon, $25 \mathrm{~cm}$; ceramic powder, $25 \mathrm{~cm}$; volcanic sand, 15 $\mathrm{cm}$; and gravel, $10 \mathrm{~cm}$.

Keywords: Cadmium (Cd); Ferro (Fe); Manganese (Mn); Quality; Water.

\section{Pendahuluan}

Pemanfaatan air tanah sebagai salah satu sumber air bersih adalah hal yang lazim dilakukan, sehingga sebagai suatu hal yang umum dalam pemanfaatan air tanah tersebut juga sering dijumpai permasalahan terhadap kualitas air tanah tersebut. Secara umum, kualitas air bersih yang dikonsumsi oleh masyarakat harus memenuhi standar kelayakan yang diatur dalam Peraturan Menteri Kesehatan Republik Indonesia Nomor 32 Tahun 2017.

Kualitas air merupakan kondisi kualitatif dari suatu contoh air yang diambil dari sumbernya yang diukur dan atau diuji berdasarkan parameter-parameter tertentu dan metode tertentu berdasarkan standar pengujian yang telah

\footnotetext{
* Corresponding Author: +6281 229453191

e-Mail: hariwahyudi.hdw@gmail.com
} 
ditetapkan dan berlaku pada waktu pengujian tersebut. Menurut standar yang ditetapkan dalam standar Peraturan Menteri Kesehatan Republik Indonesia Nomor 32 Tahun 2017, secara umum dikelompokkan menjadi 3 (tiga) parameter, yaitu : parameter fisika, kimia, dan biologi. Parameter Fisika, dalam Standar Baku Mutu Kesehatan Lingkungan untuk media air higiene sanitasi meliputi 6 (enam) parameter, yaitu : kekeruhan, warna, zat padat terlarut, suhu, rasa, dan bau. Parameter Kimia; dalam Standar Baku Mutu Kesehatan Lingkungan untuk media air higien sanitasi meliputi 10 (Sepuluh) parameter wajib dan 10 (sepuluh) parameter tambahan. Parameter kimia wajib, yaitu : $\mathrm{pH}$, besi, flourida, kesadahan $\left(\mathrm{CaCO}_{3}\right)$, mangan, nitrat, nitrit, sianida, deterjen, pestisida total. Sedangkan parameter kimia tambahan, meliputi : air raksa, arsen, kadmium, kromium, selenium, seng, sulfat, timbal, benzene, zat organik $\left(\mathrm{KMnO}_{4}\right)$. Parameter Biologi; dalam Standar Baku Mutu Kesehatan Lingkungan untuk media air higiene sanitasi terdiri dari 2 (dua) parameter yang terdiri dari total coliform dan Escherichia coli dengan satuan/unit colony forming unit dalam $100 \mathrm{ml}$ sampel air.

Fokus utama dari penelitian ini adalah membuat suatu model purwarupa instrumen sistem filter air bersih untuk menurunkan kadar besi (Fe) dalam air sumur yang berfungsi untuk memfiltrasi air sumur yang mempunyai kadar besi (Fe) tinggi menjadi air bersih yang layak konsumsi sesuai dengan standar Peraturan Menteri Kesehatan Republik Indonesia Nomor 32 Tahun 2017. Hasil penelitian diharapkan dapat memberikan manfaat berupa informasi kepada masyarakat tentang metode sederhana untuk mereduksi kadar besi dan mangan berlebih yang terdapat pada air tanah.

Menurut Puskim Balitbang Kementerian PUPR, Saringan Pasir Lambat (SPL) merupakan salah satu teknologi alternatif yang sederhana dapat dilaksanakan oleh masyarakat di pedesaan dalam memenuhi kebutuhan air bersih. Saringan Pasir Lambat (SPL), yaitu instalasi pengolahan air berupa saringan yang menggunakan pasir sebagai media filter dengan ukuran butiran sangat kecil, namun mempunyai kandungan kuarsa yang tinggi. Saringan Pasir Lambat (SPL) merupakan salah satu cara pengolahan air baku untuk menghasilkan air minum, beroperasi secara gravitasi serempak, terjadi proses fisis, proses biokimia dan proses biologis.

\section{Metode Penelitian}

Penelitian ini dilaksanakan dalam 4 (empat) tahapan pelaksanaan. Tahapan pelaksanaan penelitian tersebut diuraikan secara ringkas, sebagai berikut :

a. Tahap 1, pengambilan dan pengujian awal sampel air sumur. Sampel air diambil dari reservoir penampung air sumur bor, dimana kedalaman sumur bor berada pada 30 meter dari permukaan tanah.

b. Tahap 2, hasil uji awal sampel air sumur selanjutnya dianalisa terhadap nilai ambang batas untuk menjadi dasar perancangan filter air. unsur parameter air yang melebihi nilai ambang batas selanjutnya menjadi fokus utama untuk direduksi dengan filter hasil rancangan. c. Tahap 3, perancangan instrumen filter air. Dasar dari perancangan instrumen filter air ini adalah analisa hasil uji awal sampel air sumur.

d. Tahap 4, pengujian akhir terhadap hasil filtrasi air sumur. Hal ini dilakukan untuk mengetahui kualitas air hasil filtrasi dengan instrumen filter hasil rancangan.

\section{Hasil dan Pembahasan}

\subsection{Hasil Uji Awal}

Hasil uji kualitas contoh air baku dari sumur bor di komplek Kawasan Kampus Terpadu UPN "Veteran" Yogyakarta disajikan pada Tabel 1.

Tabel 1. Hasil uji awal kualitas air baku sumur bor di Kampus Terpadu UPN "Veteran” Yogyakarta

\begin{tabular}{|c|c|c|c|}
\hline Parameter Uji & Unit & $\begin{array}{c}\text { Nilai Batas } \\
\text { Higienis }\end{array}$ & $\begin{array}{c}\text { Nilai Hasil } \\
\text { Uji Kualitas }\end{array}$ \\
\hline \multicolumn{4}{|l|}{ A. Fisika } \\
\hline 1. Kekeruhan & NTU & 25 & 16 \\
\hline 2. Warna & TCU & 50 & 229 \\
\hline $\begin{array}{l}\text { 3. Zat Padat } \\
\text { Terlarut (TDS) }\end{array}$ & $\mathrm{mg} / \mathrm{L}$ & 1000 & 154 \\
\hline 4. Suhu & ${ }^{\circ} \mathrm{C}$ & $27 \pm 3$ & 29,6 \\
\hline 5. Rasa & & Tidak berasa & Tidak berasa \\
\hline 6. Bau & & Tidak berbau & Tidak berbau \\
\hline \multicolumn{4}{|l|}{ B. Kimia } \\
\hline 1. $\mathrm{pH}$ & $\mathrm{mg} / \mathrm{L}$ & 6,5 s.d 8,5 & 5,37 \\
\hline 2. Besi $(\mathrm{Fe})$ & $\mathrm{mg} / \mathrm{L}$ & 1,0 & $\mathbf{1 , 5 7}$ \\
\hline 3. Mangan $(\mathrm{Mn})$ & $\mathrm{mg} / \mathrm{L}$ & 0,5 & 0,682 \\
\hline $\begin{array}{l}\text { 4. Kesadahan } \\
\left(\mathrm{CaCO}_{3}\right)\end{array}$ & $\mathrm{mg} / \mathrm{L}$ & 500 & 110 \\
\hline 5. Nitrit $\left(\mathrm{NO}_{4}\right)$ & $\mathrm{mg} / \mathrm{L}$ & 1,0 & 0,061 \\
\hline 6. Flouride & $\mathrm{mg} / \mathrm{L}$ & 1,5 & 0,3 \\
\hline 7. Cyanida & $\mathrm{mg} / \mathrm{L}$ & 0,1 & 0,008 \\
\hline 8. Sulfat & $\mathrm{mg} / \mathrm{L}$ & 400 & 67 \\
\hline 9. Kadmium & $\mathrm{mg} / \mathrm{L}$ & 0,005 & $\mathbf{0 , 0 3 2}$ \\
\hline $\begin{array}{l}\text { 10. Zat Organik } \\
\left(\mathrm{KMnO}_{4}\right)\end{array}$ & $\mathrm{mg} / \mathrm{L}$ & 10 & 3,0 \\
\hline \multicolumn{4}{|l|}{ C. Biologi } \\
\hline $\begin{array}{ll}\text { 1. Total } \\
\text { Coliform }\end{array}$ & $\begin{array}{c}/ 100 \\
\mathrm{~mL}\end{array}$ & 50 & $<3,00$ \\
\hline
\end{tabular}

(Sumber: hasil uji laboratorium penulis, 2020)

Pada Tabel 1 terlihat bahwa hasil uji awal kualitas sumur bor di Kampus Terpadu UPNV Yogyakarta, terdapat beberapa parameter kualitas air, yaitu parameter fisika meliputi kekeruhan, warna, TDS, suhu, rasa, bau. Parameter kimia meliputi $\mathrm{pH}, \mathrm{Fe}, \mathrm{Mn}, \mathrm{CaCO}_{3}, \mathrm{NO}_{4}$, Flouride, Cyanida, Sulfat, Kadmium dan zat organikk $\left(\mathrm{KMnO}_{4}\right)$. Parameter biologi yaitu total coliform. Nilai hasil uji kualitas air sumur bor menunjukkan bahwa ada beberapa parameter kualitas air sumur tersebut yang melewati ambang batas nilai air higienis yaitu parameter $\mathrm{pH}$, besi $(\mathrm{Fe})$, mangan $(\mathrm{Mn})$ dan cadmium $(\mathrm{Cd})$.

Berdasarkan hasil uji awal kualitas air sumur bor tersebut, maka dapat dijadikan dasar untuk analisa dalam perancangan model filter air sehingga mampu mereduksi nilai-nilai parameter air yang belum sesuai dengan nilai 
batas air higienis dalam Standar Baku Mutu Kesehatan Lingkungan, dan diharapkan air sumur bor yang disaring dapat menjadi air bersih yang layak konsumsi sesuai Peraturan Menteri Kesehatan Republik Indonesia Nomor 32 Tahun 2017.

Selanjutnya dari hasil uji awal tersebut dilakukan analisa sebagai berikut:

\section{Nilai pH (Potential Hydrogen)}

$\mathrm{pH}$ (potential Hydrogen) merupakan skala ukuran yang digunakan untuk mengukur aktivitas ion hidrogen, yang merupakan ion pembentuk air $\left(\mathrm{H}_{2} \mathrm{O}\right)$ dan ion hidrogen ini bersifat asam. Nilai Ambang Batas (NAB) berdasarkan Permenkes RI No.32 Tahun 2017, standar baku mutu kesehatan lingkungan dan persyaratan kesehatan air untuk keperluan higien sanitasi untuk pH air sebesar 6,5 - 8,5. Hasil uji awal kualitas air pada contoh air baku dari sumur bor UPN Veteran Yogyakarta, nilai pH air sebesar 5,37.

\section{Kadar Besi (Fe)}

Hasil uji air baku menunjukkan nilai Fe yang cukup tinggi yaitu $1,57 \mathrm{mg} / \mathrm{L}$, sementara batas baku mutu air higienis $1,00 \mathrm{mg} / \mathrm{L}$. Air yang mengandung besi cenderung menimbulkan rasa mual apabila dikonsumsi, ion besi yang bersenyawa deng oksigen dan hidrogen membentuk $\mathrm{Fe}(\mathrm{OH}) 3$ dapat menyebabkan efek-efek yang merugikan yaitu mengotori bak dari seng, wastafel dan kloset, bersifat korosif terhadap pipa dan akan mengendapkan pada saluran pipa, sehingga menyebabkan pembuntuan dan menimbulkan gangguan fisik pada air dengan timbulnya warna, bau, rasa (Hanum, F., 2002). Perubahan fisik akibat ion besi dengan kadar yang besar dapat menyebabkan air menjadi berwarna coklat kemerahan (Joko, T., 2010).

\section{Kadar Mangan (Mn)}

Ion Mangan yang terkadung dalam air baku menunjukkan nilai $0,682 \mathrm{mg} / \mathrm{L}$, nilai ini diatas ambang batas syarat air higienis sebesar $0,5 \mathrm{mg} / \mathrm{L}$. Endapan $\mathrm{Mn}$ akan memberikan noda-noda pada bahan/benda-benda yang berwarna putih. Adanya unsur ini menimbulkan bau dan rasa pada minuman. Konsentrasi Mn lebih besar dari 0,5 $\mathrm{mg} /$ liter dapat menyebabkan rasa yang aneh pada minuman dan meninggalkan warna coklat pada pakaian cucian dan dapat juga menyebabkan kerusakan pada hati (Said, N.I, 2005).

\section{Kadar Kadmium (Cd)}

Kadar Kadmium (Cd) dalam air baku dari sumur bor yang berada di Kawasan Kampus Terpadu UPNV Yogyakarta, berdasarkan hasil uji memberikan nilai 0,055 $\mathrm{mg} / \mathrm{L}$, padahal nilai ambang batas yang ditentukan adalah 0,005 $\mathrm{mg} / \mathrm{L}$. Kadmium (Cd) dalam bentuk senyawa maupun ion, jika dikonsumsi dapat mengakibatkan kerusakan pada ginjal, hati, paru-paru dan tulang. Kadmium (Cd) yang masuk ke dalam tubuh terkumpul di dalam ginjal, hati dan ada sebagian yang dikeluarkan lewat saluran pencernaan. Secara umum gejala keracunan $\mathrm{Cd}$ pada manusia baik secara akut maupun kronis dapat mengakibatkan gangguan pada sistem pernapasan, kerusakan pada fungsi organ hati dan ginjal, pendarahan, gangguan terhadap pertumbuhan tulang yang menyebabkan kerapuhan tulang (Rawat et al, 2012).

\subsection{Model Filter Air}

Komposisi media filter air yang dirancang berdasarkan hasil analisa uji kualitas air baku, desain model filter air dilihat pada Gambar 1, model purwarupa tersebut terdiri dari tabung filter air yang terbuat dari pipa PVC diameter 4 inchi, dengan panjang $80 \mathrm{~cm}$. Komposisi media filter, terdiri dari: karbon aktif, tebal $25 \mathrm{~cm}$; serbuk keramik, tebal $25 \mathrm{~cm}$; pasir vulkanik, tebal $15 \mathrm{~cm}$; dan kerikil, tebal 10 $\mathrm{cm}$.

Karbon aktif merupakan material berpori-pori yang berfungsi menyerap setiap kontaminan yang melaluinya. Karbon aktif bekerja dengan cara penyerapan atau absorpsi. Karbon aktif yang digunakan pada model filter ini berasal dari arang tempurung kelapa, dan atau arang kayu. Fungsi utama karbon aktif sebagai media penyaring dan penjernih air, yaitu dengan cara; menyerap bau, menjernihkan air, mengambil klorin, dan menyegarkan air, penggunaan karbon aktif juga bertujuan untuk meningkatkan nilai $\mathrm{pH}$ air hujan sehingga memenuhi standar nilai $\mathrm{pH}$ air layak konsumsi.

Penggunaan serbuk keramik bertujuan untuk menurunkan kadar ion Kadmium (Cd) dan Zat Organik (KMnO4) yang larut dalam air hujan. Berdasarkan penelitian Febrina, L. (2015), penggunaan media filter keramik mampu mereduksi kadar ion Fe dan Mn, sampai dengan $>90 \%$. Keramik merupakan bahan yang mencakup semua benda atau sesuatu yang dapat di buat biasanya dari tanah liat atau biasa disebut tanah lempung yang melalui beberapa tahapan - tahapan seperti menggunakan energi panas atau proses pembakaran sampai bentuknya mengeras. Bahan dasar pembuatan keramik berasal dari tanah lempung yang banyak mengadung bahan kimia yang dapat di gunakan sebagai adsorben dan berfungsi untuk mengikat berbagai kation dalam proses pembuatan keramik. Lempung (clay) sebagai bahan dasar pembuatan keramik, merupakan partikel mineral tanah berukuran mikroskopis sampai dengan sub mikroskopis sekitar 0,002 mm yang berasal dari pelapukan unsur-unsur kimiawi penyusun batuan. Lempung merupakan material yang berisi air dalam persentase besar dan terjerap antara lembaran. Berdasarkan strukturnya lempung dibagi menjadi tiga kategori yaitu lempung yang dapat dijumpai dalam bentuk kristalin (crystalline minerals), struktur tidak teratur (amorphous), dan campuran (mixed layered). Sedangkan berdasarkan komposisi mineralnya lempung dapat dibedakan menjadi kaolinit, monmorilonit (smektit), ilit (clay-mica), klorit dan haloisit. Dalam penelitian ini, keramik yang digunakan adalah serbuk keramik yang berasal dari pecahan genteng. Serbuk keramik yang digunakan mempunyai ukuran keseragaman butiran yang lolos saringan no.75, dengan ukuran lubang saringan 0,12 $\mathrm{mm}$.

Menurut Kurniawati, S.D. (2017), pasir vulkanik dengan gradasi ukuran butiran yang seragam berfungsi sebagai media penyaring, demikian pula penggunaan 
kerikil yang mempunyai ukuran butiran relatif kecil dan seragam, juga bertujuan sebagai media penyaring.

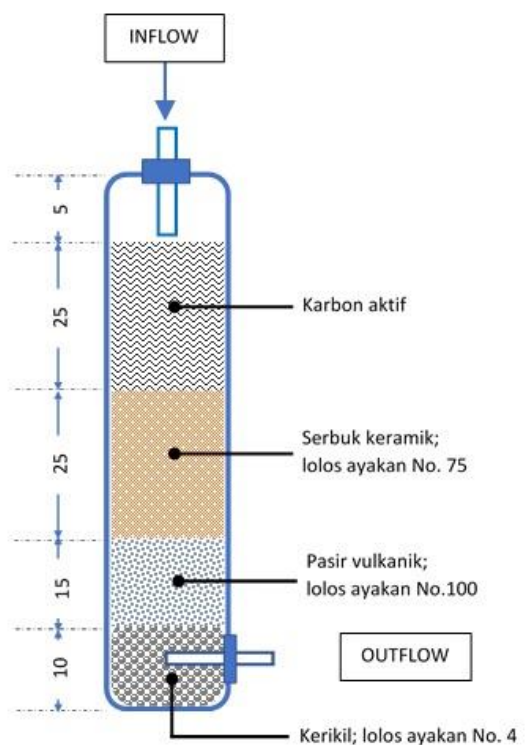

Gambar 1. Model filter air

(Sumber: Penulis, 2020)

Ukuran butiran media filter harus memenuhi kualifikasi lolos ayakan seperti pada Tabel 2.

Tabel 2. Ukuran butiran media filter

\begin{tabular}{lcc}
\hline Jenis Media Filter & $\begin{array}{c}\text { No. } \\
\text { Saringan }\end{array}$ & $\begin{array}{c}\text { Ukuran Lubang } \\
\text { Saringan (mm) }\end{array}$ \\
\hline Kerikil & 4 & 4,75 \\
Karbon aktif (arang) & 30 & 0,60 \\
Serbuk keramik & 75 & 0,12 \\
Pasir vulkanik & 100 & 0,15 \\
\hline
\end{tabular}

(Sumber: Penulis, 2020)

\subsection{Hasil Uji Air Filtrasi}

Hasil uji kualitas air setelah proses filtrasi, mengalami penurunan yang signifikan terhadap parameter yang sebelumnya melampaui Nilai Ambang Batas (NAB). Tabel 3, merupakan hasil uji kualitas terhadap parameter terlampau pada air hasil filtrasi.

Tabel 3. Hasil uji kualitas air setelah filtrasi

\begin{tabular}{|c|c|c|c|}
\hline Parameter Uji & Unit & $\begin{array}{c}\text { Nilai Batas } \\
\text { Higienis }\end{array}$ & $\begin{array}{c}\text { Nilai Hasil } \\
\text { Uji Kualitas }\end{array}$ \\
\hline \multicolumn{4}{|l|}{ B. Kimia } \\
\hline 1. $\mathrm{pH}$ & & 6,5 s.d 8,5 & 7,30 \\
\hline 2. Besi (Fe) & $\mathrm{mg} / \mathrm{L}$ & 1,0 & $\mathbf{0 , 5 8}$ \\
\hline 3. Mangan $(\mathrm{Mn})$ & $\mathrm{mg} / \mathrm{L}$ & 0,5 & 0,375 \\
\hline 4. Kadmium & $\mathrm{mg} / \mathrm{L}$ & 0,005 & $\mathbf{0 , 0 0 3}$ \\
\hline
\end{tabular}

(Sumber: Hasil uji laboratorium penulis, 2020)

\section{Kesimpulan}

Dari penelitian mengenai perancangan model filter air dengan serbuk keramik sebagai media filter, disimpulkan bahwa :

1. Hasil uji kualitas air baku dari sumber sumur bor di Kawasan Kampus Terpadu UPN Veteran Yogyakarta menunjukkan bahwa nilai $\mathrm{pH}$ air berada di bawah nilai ambang batas minimum, sehingga air baku bersifat asam. Nilai kadar ion Besi (Fe), Kadmium (Cd), dan Mangan (Mn) melampaui nilai ambang batas yang disyaratkan, sehingga perlu diturunkan supaya tidak membahayakan jika air baku dikonsumsi sebagai air bersih maupun diolah menjadi air minum.

2. Desain rancangan tabung filter air sumur terbuat dari pipa PVC diameter 4 inchi, dengan panjang $80 \mathrm{~cm}$. Komposisi media filter, terdiri dari : karbon aktif, tebal $25 \mathrm{~cm}$; serbuk keramik, tebal $25 \mathrm{~cm}$; pasir vulkanik, tebal $15 \mathrm{~cm}$; dan kerikil, tebal $10 \mathrm{~cm}$.

3. Hasil uji kualitas air sumur yang telah difiltrasi menunjukkan nilai di bawah ambang batas maksimal menurut Peraturan Menteri Kesehatan Republik Indonesia Nomor 32 Tahun 2017 tentang Standar Baku Mutu Kesehatan Lingkungan Dan Persyaratan Kesehatan Air Untuk Keperluan Higiene Sanitasi, Kolam Renang, Solus Per Aqua, dan Pemandian Umum.

\section{Ucapan Terima kasih}

Terimakasih penulis sampaikan kepada LPPM Universitas Pembangunan Nasional (UPN) Veteran Yogyakarta, yang telah memberikan dana untuk pelaksanaan penelitian ini melalui Skema Penelitian Kluster Tahun Anggaran 2020.

\section{Daftar Pustaka}

Peraturan Menteri Kesehatan Republik Indonesia Nomor 32 Tahun 2017 tentang Standar Baku Mutu Kesehatan Lingkungan Dan Persyaratan Kesehatan Air Untuk Keperluan Higiene Sanitasi, Kolam Renang, Solus Per Aqua, Dan Pemandian Umum.

Febrina, L, Ayuna, A., 2014. Studi Penurunan Kadar Besi (Fe) Dan Mangan (Mn) Dalam Air Tanah Menggunakan Saringan Keramik, Jurnal TEKNOLOGI, Vol. 7 No. 1, Januari 2015.

Hanum, F., 2002, Proses Pengolahan Air Sungai untuk Keperluan Air Minum, Program Studi Teknik Kimia, Fakultas Teknik, Digital Library Universitas Sumatera Utara.

Joko, T., 2010, Unit Air Baku dalam Sistem Penyediaan Air Minum, Graha Ilmu, Yogyakarta.

Kurniawati, S.D., Santjoko, H., Husein, A., 2017. Pasir Vulkanik sebagai Media Filtrasi dalam Pengolahan Air Bersih Sederhana untuk Menurunkan Kandungan Besi (Fe), Mangan (Mn) dan Kekeruhan Air Sumur Gali, Jurnal SANITASI , Vol. 9 No.1, Agustus 2017.

Kustiasih, T., 2014, Modul Sosialisasi dan Diseminasi Standar Pedoman dan Manual Instalasi Saringan Pasir Lambat, Pusat Penelitian dan Pengembangan 
Eksergi, Vol 18, No. 1. 2021

ISSN: $1410-394 \mathrm{X}$

Permukiman, Balitbang Kementerian Pekerjaan Umum, Bandung.

Mayasari, 2014, Analisis Kualitas Air Hujan Dan Limpasan Melalui Media Green Roof di Kampus IPB Darmaga Bogor, Skripsi.https://repository.ipb.ac.id.

Rawat,S.K., R.K Singh., R.P Singh, 2012, Remediation Of Nitrite Contamination In Ground And Surface Waters Using Aquatic Macrophytes, Jurnal Environtental Biol. 33:51-56.

Said, N.I., 2005. Metoda Penghilangan Zat Besi Dan Mangan Di Dalam Penyediaan Air Minum Domestik, Jurnal Air Indonesia BPPT, Vol. 1 No. 3, 2005. 